
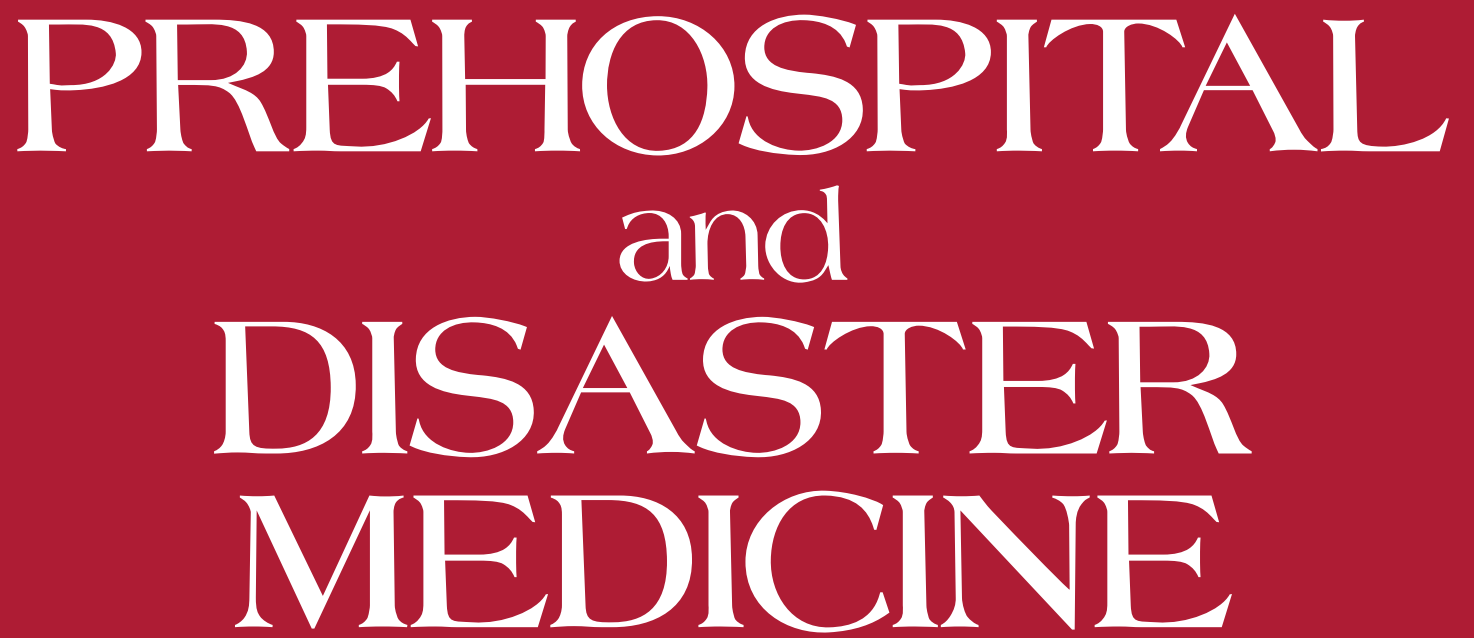

Volume 26, Number 6

December 2011
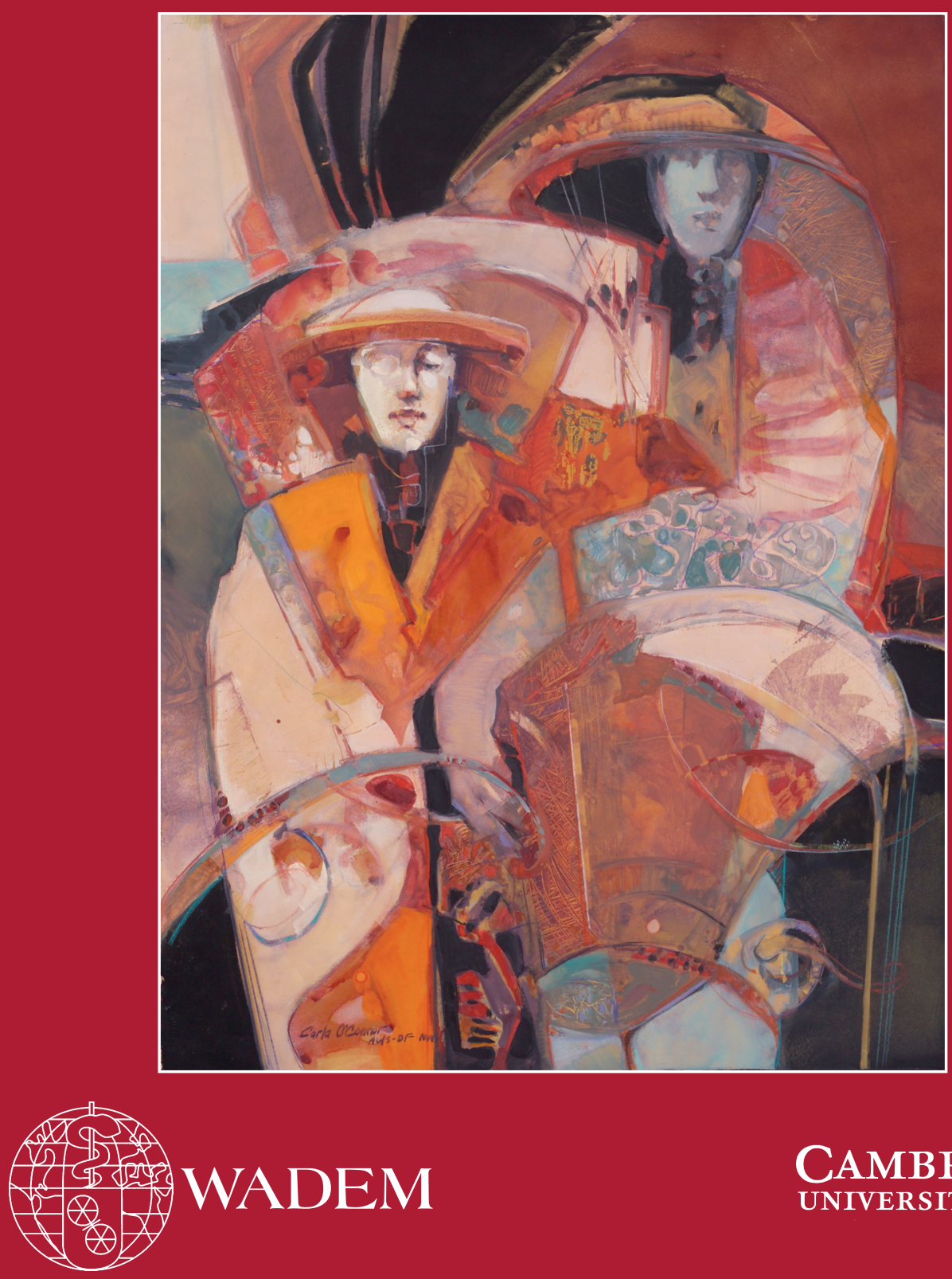

CAMBRIDGE UNIVERSITY PRESS

The Official Journal of the

World Association for Disaster and Emergency Medicine 


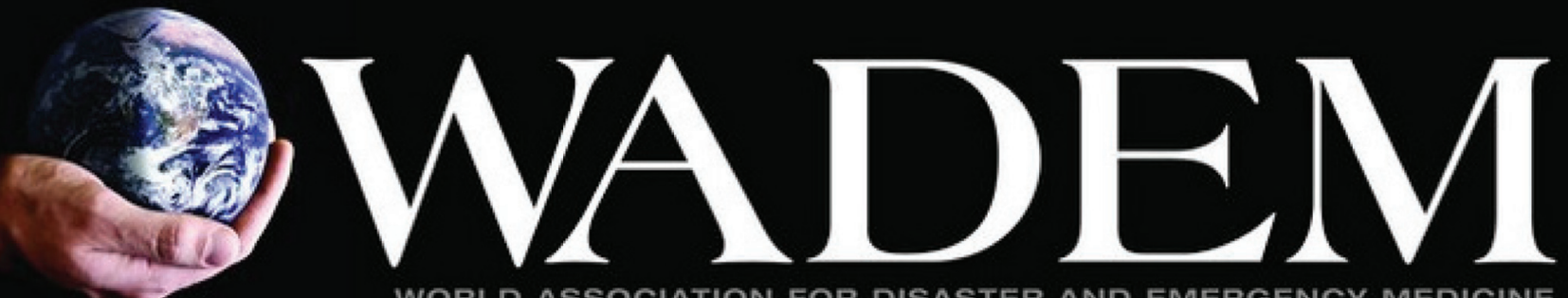

WORLD ASSOCIATION FOR DISASTER AND EMERGENCY MEDICINE

\section{SAVE THE DATE}

\section{The 4th Pan American Conference}

Topics will include:

Consensus-building

Workshops

- Disaster

Terminology

- Foreign Medical

Teams

- Accountability

- Assessments and

Measurements

Discussions and Papers

- Uses of Social Media

- New Technology

- Safe Medical

Facilities

- Forensics

- Psychosocial issues

- Roles of emergency, military, nursing, and medicine in disaster health

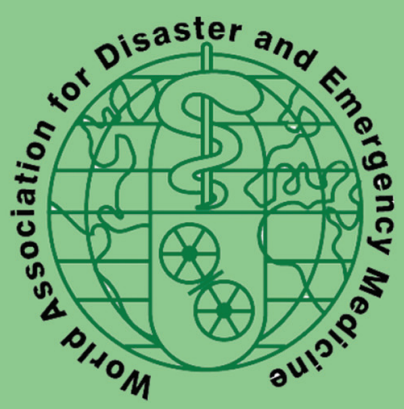

The National Conference Center

Leesburg, Virginia, USA

October 15 - 17, 2012

www.wadem.org

\section{Measuring Progress and Improving Preparedness in Disaster Management}

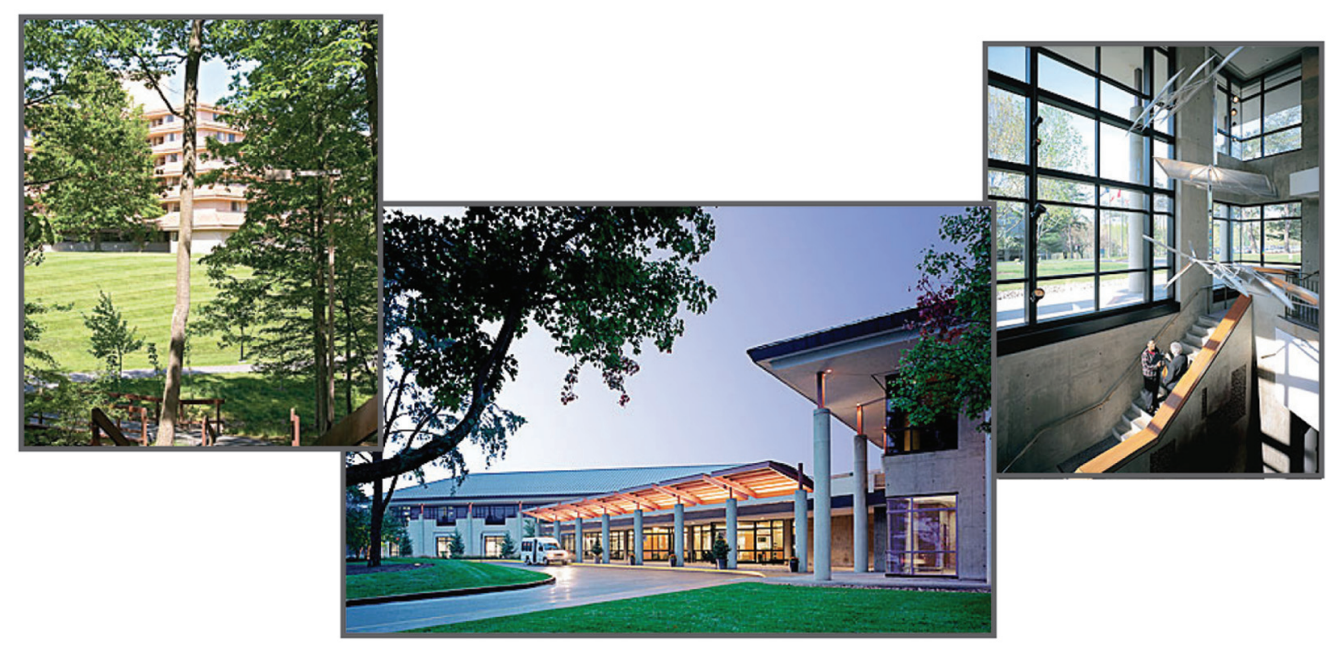

This conference will bring together individuals interested in disaster and emergency medicine/management to discuss developments in risk reduction, preparedness, and responses, and to build consensus on important related issues.

The conference will focus on risk reduction, improving preparedness, and assessing responses worldwide from prehospital care systems through post-event evaluations. There will be consensus-building workshops, debates, keynote addresses, as well as invited and free papers. Additionally, there will be several relevant pre- and postconference workshops and courses.

\section{Call for Papers}

Only 50 papers related to the above topics will be accepted.

Abstract submission opens: March 1, 2012

Deadline for submission of abstracts: May 31, 2012 


\section{Table of Contents}

\section{Editorial}

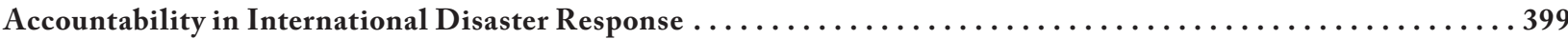
Samuel J. Stratton, MD, MPH

\section{Original Research}

Work-Related Injuries and Illnesses Reported by World Trade Center Response Workers and Volunteers ....... 401

Kara R. Perritt, MS; Robin Herbert, MD; Stephen M. Levin, MD; Jacqueline Moline, MD

Sexual Violence Trends between 2004 and 2008 in South Kivu, Democratic Republic of Congo ........... 408 Susan A. Bartels, MD, MPH; Jennifer A. Scott, MD, MBA; Jennifer Leaning, MD, SMH; Jocelyn T. Kelly, MS; Denis Mukwege, MD; Nina R. Joyce, MPH; Michael J. VanRooyen, MD, MPH

Assessing the Psychosocial Elements of Crowds at Mass Gatherings $\ldots \ldots \ldots \ldots \ldots \ldots \ldots \ldots$ Alison Hutton, RN, PhD; Kathryn Zeitz, RN, PhD; Steve Brown, PhD; Paul Arbon, RN, PhD

Prehospital Analgesia in New South Wales, Australia

Jason C. Bendall, MBBS, MM (ClinEpi), PhD; Paul M. Simpson, MScMed (ClinEpi);

Paul M. Middleton, MBBS, MM (ClinEpi), $M D$

\section{Letters to the Editor}

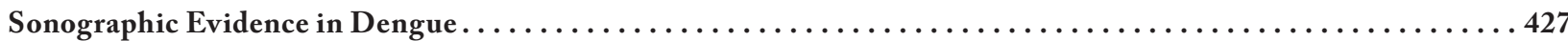

Viroj Wiwanitkit, $M D$

\section{Papers from the Harvard Humanitarian Initiative's 4th Annual Humanitarian Action Summit}

Best Practice Guidelines on Surgical Response in Disasters and Humanitarian Emergencies: Report of the 2011 Humanitarian Action Summit Working Group on Surgical Issues

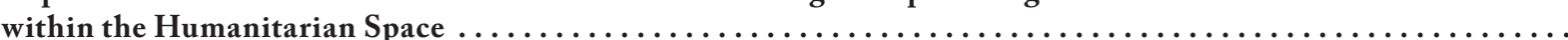
Smita Chackungal, MD, MPH; Jason W. Nickerson, RRT, PhD(c); Lisa M. Knowlton, MD, MPH; Lynn Black, MD, MPH; Frederick M. Burkle, Jr, MD, MPH, DTM; Kathleen Casey, MD; David Crandell, MD; Didier Demey, Lillian DiGiacomo, MD, MPH(c); Lena Dohlman, MD, MPH; Joshua Goldstein; James E. Gosney, Jr, MD, MPH; Keita Ikeda, PhD; Allison Linden, MD, MPH(c); Catherine M. Mullaly, MD, MPH; Colleen O'Connell, MD; Anthony D. Redmond, MD; Adam Richards, MD, MPH; Robert Rufsvold, MD; Ana L.R. Santos, MSc; Terri Skelton, MD; Kelly McQueen, MD, MPH

Consensus Statements Regarding the Multidisciplinary Care of Limb Amputation Patients in Disasters or Humanitarian Emergencies: Report of the 2011 Humanitarian Action Summit Surgical Working Group on Amputations Following Disasters or Conflict . . . . . . . . . . . . . 438 Lisa Marie Knowlton, MD, MPH; James E. Gosney, Jr, MD, MPH; Smita Chackungal, MD, MPH; Eric Altschuler, MD, PhD; Lynn Black, MD, MPH; Frederick M. Burkle Jr, MD, MPH, DTM; Kathleen Casey, MD; David Crandell, MD; Didier Demey; Lillian DiGiacomo, MD, MPH(c); Lena Dohlman, MD, MPH; Joshua Goldstein; Richard Gosselin, MD, MPH; Keita Ikeda, PhD; Andree LeRoy, MD; Allison Linden, MD, MPH(c); Catherine M. Mullaly, MD, MPH; Jason Nickerson, RRT, PhD(c); Colleen O'Connell, MD; Anthony D. Redmond, MD; Adam Richards, MD, MPH; Robert Rufsvold, MD; Anna L.R. Santos, MSc; Terri Skelton, MD; Kelly McQueen, MD, MPH

A Qualitative and Quantitative Study of the Surgical and Rehabilitation Response to the Earthquake in Haiti, January 2010. 449 Anthony D. Redmond, MD; Simon Mardel, MB; Bertrand Taithe, PhD; Thomas Calvot, Dip MK; Jim Gosney, MD; Anthony Duttine, MA; Susan Girois, MD 
Health Diplomacy and Humanitarian Action: Uncharted Territory

Valerie Percival, $M A, D r P H$

Urbanization and Humanitarian Access Working Group: A Blueprint for the Development of Prevention and Preparedness Indicators for Urban Humanitarian Crises. . . . . . . . . . . . . . . . . . . 460 Shada A. Rouhani, MD; Ronak B. Patel, MD, MPH; Laura M. Janneck, MD, MPH; Amit Prasad MA, MPA/ID; Jostacio Lapitan MD, MPH; Frederick M. Burkle, Jr, MD, MPH, DTM

Urbanization and Humanitarian Access Working Group: Toward Guidelines for Humanitarian Standards and Operations in Urban Settings

Laura M. Janneck, MD, MPH; Ronak Patel, MD, MPH; Shada A.Rouhani, MD;

Frederick M. Burkle, Jr, MD, MPH, DTM

Transitioning Mental Health \& Psychosocial Support: From Short-Term Emergency to Sustainable

Post-Disaster Development. Humanitarian Action Summit 2011

P.P. Patel, JD, MPH; J. Russell, PhD; K. Allden, MD; T.S. Betancourt, ScD, MA; P. Bolton, MBBS, MPH;

A. Galappatti, MSc; Z. Hijazi; K. Johnson, MD, MPH; L. Jones, OBE, MRCPsych; L. Kadis, MD;

K. Leary, Ph.D., ABPP; I. Weissbecker, PhD, MPH; J. Nakku, MBChB, M.MED(Psychiatry)

Innovations in Humanitarian Technologies Working Group-Report of the Proceedings,

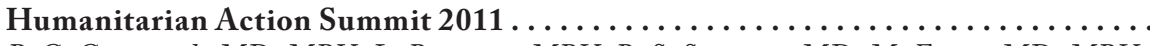

P. G. Greenough, MD, MPH; L. Bateman, MPH; B. S. Sorensen, MD; M. Foran, MD, MPH 


\section{Editorial Office}

World Association for Disaster and Emergency Medicine (WADEM), Madison,

Wisconsin USA

Editor-in-Chief

Samuel J. Stratton, MD, MPH

\section{Development Editor \\ Mona Johnson}

Editorial Assistant

Jackson Helmer

Publisher

Cambridge University Press

32 Avenue of the Americas

New York, NY 10013-2473 USA
Prehospital and Disaster Medicine (ISSN 1049-023X) is published bimonthly in the months of February, April, June, August, October, December, by Cambridge University Press for the World Association for Disaster and Emergency Medicine. Prehospital and Disaster Medicine incorporates the Journal of the World Association for Emergency and Disaster Medicine and the Journal of Prehospital Medicine.

Editorial Information: All manuscripts must be submitted through the Journal's online submission platform, ScholarOne Manuscripts: http://mc. manuscriptcentral.com/pdm.

Subscription Information: Institutions print and electronic: US $\$ 460.00$ in the USA, Canada, and Mexico; UK£288.00+VAT elsewhere. Institutions electronic only: US\$345.00 in the USA, Canada, and Mexico; UK£216.00+VAT elsewhere. Individuals print and electronic: US $\$ 138.00$ in the USA, Canada, and Mexico; UK£86.00+VAT elsewhere. Individuals electronic only: US $\$ 104.00$ in the USA, Canada, and Mexico; UK£65.00+VAT elsewhere. Single Part: US\$85.00 in the USA, Canada, and Mexico; UK£53.00+VAT elsewhere. Prices include postage and insurance. Airmail or registered mail is extra. Back volume prices are available upon request. Claims of non-receipt or damaged issues must be filed within three months of cover date.

Comprehensively indexed by the National Library of Medicine (MEDLINE), Cumulative Index to Nursing and Allied Health (CINAHL) and Health Star Cumulative Index. The database is available online via BRS, Data-Star, and DIA-LOG, and on CD-ROM through CD Plus, Compact Cambridge and Silver Platter. Abstracts and search capability available on the Internet at http://pdm.medicine.wisc.edu.

Copyright (C) 2012 by the World Association for Disaster and Emergency Medicine.

\section{Cover Artwork}

Time Travelers, a watermedia painting (watercolor and gouache) by Carla O'Connor

Carla O'Connor received her BFA in painting from Kent State University, Kent, Ohio. She has completed additional formal study at the University of the Americas, Mexico City; University of Dayton, Ohio; and the University of Wisconsin, Milwaukee.

She is a signature member of the American Watercolor Society, National Watercolor Society and Northwest Watercolor Society and is an AWS Dolphin Fellow.

O'Connor has juried for national and international art exhibits including AWS and NWS, the Rocky Mountain National Exhibition, California Watercolor Society and the Watercolor Art Society - Houston. She also served as chairman of the awards jury for the AWS International Exhibition in 2008. O'Connor participated in the First Invitational Exhibition of Contemporary International Watermedia Masters, Nanjing, China, 2007 and 2009 and the Shanghai Zhujiajiao Exhibition, 2010.

Carla is the recipient of many awards from organizations such as the National Watercolor Society and the American Watercolor Society, including the AWS Silver Medal. Her work has appeared in numerous publications including Nita Leland's "Exploring Color" and "The New Creative Artist" as well as "Splash 5 - The Glory of Color". She has authored articles for U.S. publications including The Artist Magazine, International Artist Magazine, Watercolor Magic, Watercolor, and American Watercolor Magazines. Her work appeared in The Artist in the United Kingdom and L'Art De L'Aquarelle in France.

O'Connor teaches workshops throughout the year in the U.S. and abroad, and her teaching DVD, "Figure Design in Gouache - The Process" was released in July of 2008.

For more information, please go to www.carlaoconnor.com 
EDITOR-IN-CHIEF

Samuel Stratton, MD, MPH

University of California-Los

Angeles

Los Angeles, California, USA

\section{EMERITUS EDITOR-}

IN-CHIEF

Marvin L. Birnbaum, MD, PhD

University of Wisconsin-

Madison

Madison, Wisconsin, USA

\section{DEPUTY EDITORS}

David A. Bradt, MD, MPH

Royal Melbourne Hospital

Melbourne, Australia

Geert Seynaeve, MD

Brussels, Belgium

Darren Walter

University Hospital of South

Manchester

Manchester, UK

\section{ASSOCIATE EDITORS}

Wolfgang F. Dick, MD,PhD

Mainz, Germany

\section{Kimball Maull, MD, FACS}

Department of Surgery

Hamad General Hospital

Doha, Qatar

Steven Rottman, MD

University of California-

Los Angeles

Los Angeles, California, USA

\section{SECTION EDITOR}

Humanitarian Affairs

Frederick M. Burkle, MD, MPH, DTM

Senior Fellow and Scientist,

Harvard Humanitarian

Initiative

Harvard University

Cambridge, Massachusetts, USA
Senior Public Policy Scholar

Woodrow Wilson International

Center for Scholars

\section{EDITORIAL BOARD \\ Carol Amaratunga, PhD \\ Adjunct Professor \\ Claude de Ville de Goyet, MD \\ Brussels, Belgium}

School of Child and Youth

Development

University of Victoria Research

Associate of the Justice Institute

of British Columbia Canada

Paul Arbon, PhD

School of Nursing and

Midwifery

Flinders University

Adelaide, South Australia

Frank Archer, MD

Monash University

Melbourne, Australia

Jeffery Arnold, MD

Department of Emergency Medicine

Santa Clara Valley Medical

Center

San Jose, California, USA

Yaron Bar-Dayan, MD, MHA

Israeli Defense Forces Home

Front Command

Or-Yehuda, Israel

Joost Bierens, MD, PhD

Amsterdam, The Netherlands

Tareg Bey, MD

Department of Emergency Medicine

University of California-Irvine, Irvine, California, USA

Richard A. Bissell, PhD

University of Maryland-Baltimore

Baltimore, Maryland, USA

Felipe Cruz-Vega, MD

Office of Social Security

Mexico City, Mexico
Robert A. De Lorenzo, MD, MSM, FACEP

Medical Corps

United States Army

San Antonio, Texas, USA

Judith Fisher, MD

Consultant

Washington, DC, USA

Erik S. Gaull

George Washington University

Washington, DC, USA

\section{Michael Gunderson}

President

Integral Performance Solutions

Lakeland, Florida, USA

Keith Hotlermann, MD

George Washington University

Washington, DC, USA

Mark Johnson, MPA

Retired Chief of EMS

Juneau, Alaska, USA

Mark Keim, MD

Center for Disease Control and

Prevention

Atlanta, Georgia, USA

Todd J. LeDuc, EMT-P

Deputy Fire Chief

Broward Sheriff Fire Rescue

Ft. Lauderdale, Florida, USA

Gloria Leon, PhD

Professor of Psychology

University of Minnesota

Minneapolis, Minnesota, USA

Graeme McColl

Emergency Management Team

National Health Board

Ministry of Health

Christchurch, New Zealand

Andrew Milsten, MD, MS, FACEP

University of Massachusetts

Emergency Medicine

Baltimore, Maryland, USA
Jerry Overton

President/CEO

Chairman

IAED Emergency Clinical Advice System \& Standards Board

Salt Lake City, Utah, USA

Paul Paris, MD

Center for Emergency Medicine

University of Pittsburgh

Pittsburgh, Pennsylvania, USA

Lynda Redwood-Campbell, MD, MPH

Department of Family Medicine

McMaster University,

Hamilton, Ontario, Canada

Edward Ricci, PhD

University of Pittsburgh

Pittsburgh, Pennsylvania, USA

Leonid Roshal, MD

Institute of Pediatrics

Academy of Medical Sciences

Moscow, Russia

Don Schramm

University of Wisconsin-Madison

Madison, Wisconsin, USA

Knut Ole Sundnes, MD

Baerum Hospital

Oslo, Norway

Takashi Ukai, MD

Hyogo Emergency Medical Center

Hyogo, Japan

Michael Van Rooyen, MD

Associate Professor, Harvard Medical School, Brigham and Women's Hospital

Boston, Massachusetts, USA 
Aims and Scope: The mission of Prehospital and Disaster Medicine (PDM) is the distribution of information relevant to the practice of out-of-hospital and in-hospital emergency medical care, disaster health, and public health and safety. PDM provides an international forum for the reporting and discussion of scientific studies, both quantitative and qualitative, that have relevance to the above practices. The major objectives are: (1) the improvement of the types and quality of the care delivered to patients with perceived medical emergencies and to victims of multi-casualty accidents or disasters, including the public health and safety aspects of such events; and (2) the prevention and/or mitigation of the occurrence of such events and of the effects of these events upon the human population and environment.

Editorial Office: Prehospital and Disaster Medicine, 3330 University Avenue, Suite 130, Madison, Wisconsin 53705, USA. Telephone: (+1) (608) 819-6604; Facsimile (+1) (608) 819-6055; E-mail: pdm@wadem.org

Publishing, Production, and Advertising Office: Cambridge University Press, 32 Avenue of the Americas, New York, NY 10013-2473, United States.

Subscription Offices: (for USA, Canada, and Mexico) Cambridge University Press, 32 Avenue of the Americas, New York, NY 10013-2473, United States; (for UK and elsewhere) Cambridge University Press, The Edinburgh Building, Shaftesbury Road, Cambridge CB2 8RU, UK.

2012 Subscription Information: Prehospital and Disaster Medicine (Print ISSN 1049-023X; Electronic ISSN 1945-1938) is published bimonthly in the months of February, April, June, August, October, and December by Cambridge University Press, 32 Avenue of the Americas, New York, NY 10013-2473, United States/Cambridge University Press, The Edinburgh Building, Shaftesbury Road, Cambridge CB2 8RU, UK for the World Association for Disaster and Emergency Medicine. 2011 Annual subscription rates: Institutions print and electronic: US\$516.00 in the USA, Canada, and Mexico; UK£313.00+VAT elsewhere. Institutions electronic only: US\$375.00 in the USA, Canada, and Mexico; UK£227.00+VAT elsewhere. Individuals print and electronic: US $\$ 153.00$ in the USA, Canada, and Mexico; UK£93.00+VAT elsewhere. Individuals electronic only: US $\$ 113.00$ in the USA, Canada, and Mexico; UK£68.50+VAT elsewhere. Single Part: US\$94.00 in the USA, Canada, and Mexico; UK£57.00+VAT elsewhere. Prices include postage and insurance. Airmail or registered mail is extra. Back volume prices are available upon request.

Indexing: National Library of Medicine (MEDLINE), Cumulative Index to Nursing and Allied Health (CINAHL), and Heath Star Cumulative Index.

(C) World Association for Disaster and Emergency Medicine 2012. All rights reserved. No part of this publication may be reproduced, in any form or by any means, electronic, photocopying, or otherwise, without permission in writing from Cambridge University Press. Policies, request forms, and contacts are available at: http://www.cambridge.org/rights/permissions/permission. $\mathrm{htm}$. Permission to copy (for users in the United States) is available from Copyright Clearance Center Transactional Reporting Service, 222 Rosewood Drive, Danvers, MA 01923, USA. http://www.copyright.com, email: info@copyright.com.

Printed in United States of America on acid-free paper.

Postmaster: Send address changes in the USA and Canada to Prehospital and Disaster Medicine, Subscription Department, Cambridge University Press, 100 Brook Hill Drive, West Nyack, NY 10994-2133, USA.

Periodical postage rate paid at New York, NY and additional mailing offices. 


\section{INSTRUCTIONS FOR AUTHORS}

\section{Editorial Policy}

Manuscripts in one of five different categories can be submitted for review and publication in Prehospital and Disaster Medicine (PDM): (1) Original Research; (2) Special Report; (3) Comprehensive Review; (4) Case Report; or (5) Brief Report.

All manuscripts submitted for publication must include an abstract that summarizes the work. Other types of manuscripts must have the approval of the Editor before being submitted or may be invited by the Editor or a member of the Editorial Board.

The characteristics specific to each of these categories are described briefly below:

1. Original Research-structured research that uses quantitative and/or qualitative data collection methods and analyses to establish a hypothesis or prove a cause: effect relationship(s) is included in this category. The manuscript must be structured as follows:

Abstract-concise summary in the following format (not to exceed 375 words):

Introduction: What is the need for the study.

Hypothesis/Problem: What was tested (experimental studies only). If qualitative, statement of problem addressed.

Methods: Summary of methods used with subsections as appropriate (type of subjects, number of subjects, study design, statistical tests). If the work is qualitative, the types of instruments used and the scope and type of work must be described. If a disaster is involved, the dates, type of event, location, scope, magnitude, and numbers of casualties and deaths must be summarized in tabular form for indexing.

Results: Summary of principal findings.

Conclusion: Implications of findings.

Introduction-provide justification for the effort with appropriate references annotated. If quantitative, the concluding sentence should define the hypothesis. If qualitative, the problem being addressed should be stated clearly.

Methods-descriptive to a degree that other investigators would be able to reproduce the study. Statistical methods used must be annotated. Approval by an Institutional Review Committee must be included when appropriate.

Results-results must be written in text and may be accompanied by tables and figures. The text must explain all data included in tables and figures, but should not be unnecessarily redundant. All direct results from the study must appear in this section. No discussion of the results may be included.

Discussion - the discussion should provide an interpretation of the results in terms of meaning and application. Results should not be repeated. Computations or extrapolations that may help explain the results may be provided. Limitations of the study should be defined and suggestions for future research should be included. References that support or negate explanations provided are appropriate.

Conclusion-the findings in terms of implications for the practice of prehospital, emergency, and/or disaster (humanitarian) medicine should be summarized in a few sentences.

2. Special Report-describes some aspect of our science or activities that provide information necessary for the progression of the science. The
Introduction should highlight the problem being addressed and the reasons that it needs to be addressed. Sections of the report should be subtitled. The presentation should include citations as to the sources of the material and should be followed by a discussion that includes the significance of the report in terms of the science. The manuscript should be finished with the conclusions reached.

3. Comprehensive Review-a review of the literature to be used to clarify areas in which there seems to be disagreement. Comprehensive reviews seek to establish the evidence-base for the area being addressed. The format used should be identical to that described for special reports.

4. Case Report-uses one or more cases of specific patients or events/ responses to highlight a current aspect of medical care or of a phenomenon. Case reports also may have value in the development of definitive research projects by the same or other investigators. The Introduction should describe the reasons for the report. The actual case report(s) should be described in the next section, and like the above, the discussion should describe the significance of the reports including a comprehensive review of the pertinent literature. The conclusion should be similar to the format noted above.

5. Brief Report-a short report that may predict a trend, but the work does not meet all of the criteria required for original research. Preliminary reports also are included in this category. The format used should be identical to that used for the original research described above.

6. Congress Abstracts-All abstracts submitted by the Secretariat of a Congress will be edited by the Editorial Staff into the best English possible prior to publicaiton.

\section{Submission of Manuscripts}

All manuscripts must be submitted through the Journal's online submission platform, ScholarOne Manuscripts: http://mc.manuscriptcentral.com/pdm.

The following must be included with the submitted manuscript:

Cover Letter-each manuscript should be accompanied by a cover letter stating the following:

- The primary author who attests to the original nature of the material, that the paper has not been published elsewhere, is not under consideration by any other publication

- That the authors agree to transfer copyright to Prehospital and Disaster Medicine if accepted for publication.

- The institution(s) in which the work was performed, the sponsoring institution(s), and the respective departments must be annotated.

- If the work was supported all or in part by grants or endowments, the granting institution(s) should be indicated.

- If the paper has been, or is to be presented in a forum orally or as a poster, indicate the title of the forum, sponsoring institution, and the date of presentation.

- Specify the name of the author with whom any correspondence should be directed, and, correspondence street address, telephone number, fax number, and email address if appropriate. Abbreviations for groups of words may be used only for unusually cumbersome titles or for commonly accepted abbreviations. Whenever such abbreviations are used, they must be annotated with the initial mention of words within the manuscript followed by the abbreviation in parentheses. 
- In addition, list three to five keywords or phrases in alphabetical order separated by semicolons to facilitate indexing or electronic searches.

Cover Page - include a cover page that includes the title of the paper, first names, middle initials, last names, and highest academic degrees of all authors. Reiterate from the cover letter the name of the author with whom any correspondence should be directed and the street address, telephone number, fax number, and email address if appropriate. Do not indicate author names or institutions anywhere in the manuscript other than on the cover page.

Language-all manuscripts must be submitted in English. Also, do not use $I, W e$, or Our when describing the researchers. The fact that the research was conducted by the authors is implicit.

Margins, and Type Style-Use standard type styles. Do not use bold, italicized, superscript, or subscript characters. Double space all text.

Generic Names-whenever possible, use generic names. Brand names may be indicated parenthetically and the name and location of the manufacturer must be provided in parentheses followed by a generic description of the medication, drug, product, or equipment.

Copyright-after acceptance for publication, the copyright to the manuscript, including all tables and figures, rests with Prehospital and Disaster Medicine.

\section{References}

References must be cited in the sequential order in which they appear in the text. All references should be parenthetically cited by full-sized Arabic numbers in the text, tables, and legends for illustrations. Titles of journals referenced must be annotated using standard Index Medicus abbreviations and must be in italics. Do not use automatic numbering in the References section. Unpublished data or personal communications should be indicated in parentheses directly following the reference and should include the dates of such correspondence (Personal Communication, Safar P, October 1989). The following format for references must be used:

Journals-White SJ, Hamilton WA, Veronesi JF: Comparison of field techniques used to pressure infuse intravenous fluids. Prehosp Disaster Med 1991; 6(4):429-434.

Books-Schwartz GR, Safar P, Stone JH, et al (eds), Principles and Practice of Emergency Medicine. 2d ed. Philadelphia: WB Saunders Co., 1985, pp 1198-1202.

Chapters-Lindberg R: Pathology of Head Injuries. In: Cowley RA, Trump BF (eds), Pathophysiology of Shock. Baltimore: Williams and Wilkins, 1982, pp 588-592.

Website-International Crisis Group: Impact of the Bali bombings. In: Indonesia Briefing, Jakarta/Brussels. Available at http://www. crisisweb.org/projects/asia/indonesia/reports/A400804_24102002.pdf. Accessed 09 June 2003.

\section{Figures and Tables}

Only essential figures and tables should be included. Further tables, figures, photographs and appendices, may be included with the online version on the journal website.
Photographs Photographs should be submitted electronically through the Journal's online submission platform: http://mc.manuscriptcentral.com/pdm and be at least $600 \mathrm{dpi}$ resolution. Color illustrations must be discussed with the editor. The printed version will normally be reduced to $70 \mathrm{~mm}$ wide, so care should be taken to ensure that lettering and symbols will remain clearly legible.

To ensure that your figures are reproduced to the highest possible standards and your article is published as quickly and efficiently as possible, Cambridge Journals recommends the following formats and resolutions for supplying electronic figures. Please note that submitting low quality figures may result in a delay in publishing your valuable research.

Please ensure that your figures are saved at final publication size (plesae see the latest issue of the journal for column widths) and are in our recommended file formats. Following these guidelines will result in high quality images being reproduced in both the print and the online versions of the journal.

\section{Line artwork}

Format: tif or eps

Color mode: black and white (also known as 1-bit)

Size: please size to final publication size

Resolution: 1200 dpi

Combination artwork (line/tone)

Format: tif or eps

Color mode: grayscale (also known as 8-bit)

Size: please size to final publication size

Resolution: 800 dpi

\section{Black and white halftone artwork}

Format: tif

Color mode: grayscale (also known as 8-bit)

Size: please size to final publication size

Resolution: 300 dpi

\section{Color halftone artwork}

Format: tif

Color mode: CMYK color

Size: please size to final publication size

Resolution: 300 dpi

All graphs, and diagrams should be referred to as figures and should be numbered consecutively in Arabic numerals.

Permissions-illustrations or tables from other publications must be accompanied by written permission from the author and publishers of the document in which they originally appeared.

\section{Proofs and offprints}

Page proofs will be sent to the author designated to receive correspondence. Corrections other than to printer's errors may be charged to the author. A final PDF version of the article will be supplied to the corresponding author when the article is published. 